\title{
The intestinal microbial composition in Greylag geese differs with steatosis induction mode: spontaneous or induced by overfeeding
}

Christelle Knudsen $^{1 *}$ (D) Julien Arroyo ${ }^{2}$, Maxime Even ${ }^{3}$, Laurent Cauquil ${ }^{1}$, Géraldine Pascal ${ }^{1}$, Xavier Fernandez $^{1}$, Franck Lavigne ${ }^{2}$, Stéphane Davail ${ }^{3}$, Sylvie Combes $^{1}$ and Karine Ricaud ${ }^{3}$

\begin{abstract}
Background: Relationships between microbial composition and steatosis are being extensively studied in mammals, and causal relations have been evidenced. In migratory birds the liver can transiently store lipids during pre-migratory and migratory phases, but little is known about the implications of the digestive microbiota in those mechanisms. The Landaise greylag goose (Anser anser) is a good model to study steatosis in migratory birds as it is domesticated, but is still, from a genetic point of view, close to its wild migratory ancestor. It also has a great ingestion capacity and a good predisposition for hepatic steatosis, whether spontaneous or induced by conventional overfeeding. The conventional (overfeeding) and alternative (spontaneous steatosis induction) systems differ considerably in duration and feed intake level and previous studies have shown that aptitudes to spontaneous steatosis are very variable. The present study thus aimed to address two issues: (i) evaluate whether microbial composition differs with steatosis-inducing mode; (ii) elucidate whether a digestive microbial signature could be associated with variable aptitudes to spontaneous liver steatosis.
\end{abstract}

Results: Performances, biochemical composition of the livers and microbiota differed considerably in response to steatosis stimulation. We namely identified the genus Romboutsia to be overrepresented in birds developing a spontaneous steatosis in comparison to those submitted to conventional overfeeding while the genera Ralstonia, Variovorax and Sphingomonas were underrepresented only in birds that did not develop a spontaneous steatosis compared to conventionally overfed ones, birds developing a spontaneous steatosis having intermediate values. Secondly, no overall differences in microbial composition were evidenced in association with variable aptitudes to spontaneous steatosis, although one OTU, belonging to the Lactobacillus genus, was overrepresented in birds having developed a spontaneous steatosis compared to those that had not.

Conclusions: Our study is the first to evaluate the intestinal microbial composition in association with steatosis, whether spontaneous or induced by overfeeding, in geese. Steatosis induction modes were associated with distinct digestive microbial compositions. However, unlike what can be observed in mammals, no clear microbial signature associated with spontaneous steatosis level was identified.

Keywords: Anser anser, Gut microbiota, Fatty liver, Migratory bird

\footnotetext{
* Correspondence: christelle.knudsen@inrae.fr

${ }^{1}$ GenPhySE, Université de Toulouse, INRAE, ENVT, F-31326 Castanet Tolosan,

France

Full list of author information is available at the end of the article
}

(C) The Author(s). 2021 Open Access This article is licensed under a Creative Commons Attribution 4.0 International License, which permits use, sharing, adaptation, distribution and reproduction in any medium or format, as long as you give appropriate credit to the original author(s) and the source, provide a link to the Creative Commons licence, and indicate if changes were made. The images or other third party material in this article are included in the article's Creative Commons licence, unless indicated otherwise in a credit line to the material. If material is not included in the article's Creative Commons licence and your intended use is not permitted by statutory regulation or exceeds the permitted use, you will need to obtain permission directly from the copyright holder. To view a copy of this licence, visit http://creativecommons.org/licenses/by/4.0/. 


\section{Background}

In birds, unlike mammals, the liver represents the main lipid synthesis site and can transiently store lipids, as it is the case in migratory birds during pre-migratory and migratory phases although storage mainly occurs in peripheral adipose tissues [1,2]. During the pre-migratory phase increased feed intake is the main contributor to overall fattening [3], but increased digestive efficiency has also been observed, although variable between species [4].

The Landaise greylag goose (Anser anser) is a good model to study steatosis in migratory birds as it is domesticated, and can therefore be easily bred in experimental conditions, but is still, from a genetic point of view, close to its wild migratory ancestor [5]. It also has a great ingestion capacity and a good predisposition for hepatic steatosis, whether spontaneous [6] or induced by conventional overfeeding [7]. However, this last practice is highly questioned today for animal welfare reasons. Research is therefore being conducted to seek for alternative and more ethical methods without overfeeding to produce waterfowl fatty liver. In experimental conditions, spontaneous steatosis has been induced [6] by mimicking pre-migratory conditions, performing trials during winter season with a reduction in day length and alternations in food availability with a restricted access to a pellet diet followed by 12 weeks of ad libitum corn feeding. However, rearing time, and consequently overall feed intake and environmental impacts, are drastically increased with a liver weight that is halved compared to the conventional system based on overfeeding [8]. Previous studies using this experimental setup have also evidenced high variability in the aptitude to spontaneous steatosis (45-65\% in variability coefficient with an average liver weight increase from around $90 \mathrm{~g}$ to $500 \mathrm{~g}$ ) that can in part be explained by the inter-individual variability in feed intake $[6,9]$. Other parameters such as genetics and the digestive microbiota could however contribute to this variability. Indeed, in mammals growing evidence suggests that alterations in the digestive microbiota can contribute to the onset and progression of Non Alcoholic Fatty Liver Disease (NAFLD), although diet plays the main role in the etiology of this disease (for review, [10]). The digestive microbiota could then be another contributing factor to the variable aptitude to spontaneous steatosis but also a potential actor on feeding behavior [11] in geese.

Few studies have assessed associations between the microbiota and steatosis in greylag geese, or migratory birds. In waterfowl, studies have focused on overfed ducks [12-14] and geese [15]. However, overfeeding differs greatly from spontaneous steatosis induction in duration (16 days vs 12 weeks in geese), daily feed intake level and average liver weight (1000 vs $500 \mathrm{~g}$ ), variability
(20 vs 45-60\%) [16] and chemical composition [17]. Also, in conventional overfeeding, feed intake being controlled, no impact of the digestive microbiota on feed intake can be evaluated. The present study thus aimed to address two issues. First, as the conventional (overfeeding) and alternative (spontaneous steatosis induction) systems differ considerably, we wanted to evaluate whether microbial composition differed with steatosisinducing mode. Second, we wanted to elucidate whether the digestive microbiota could be correlated with variable aptitudes to spontaneous liver steatosis.

\section{Methods}

The in vivo experiment was performed between July 2015 and February 2016 at the Goose and Duck Breeding Station (Coulaures, France; experimental approval A24-137-1). Technical staff and scientists all had individual authorizations to conduct animal experimentation in accordance with good animal practices issued by the DDCSPP (Direction Départementale de la Cohésion Sociale et de la Protection des Populations) and slaughter was performed according to the European Council regulations [18]. All diets used during the rearing period met the National Research Council's (NRC) requirements [19] and were manufactured by Sanders Périgord (Boulazac, Dordogne, France).

\section{Feeding programs and housing management}

Eighty five male 43-day-old Greylag Landaise geese (Maxipalm ; Anser anser) were reared in housing, feeding and management conditions as previously described [20] given a grower-finisher diet (Apparent metabolizable energy corrected for nitrogen (AMEn) $11.5 \mathrm{MJ} / \mathrm{kg}$, Crude Protein (CP) $161 \mathrm{~g} / \mathrm{kg}$ ) ad libitum until 56 days of age. After that, access to the grower finisher diet was limited to 2 to $3 \mathrm{~h}$ /day.

At 91 days of age, birds were separated in two experimental systems, a "conventional" system (Conv., $n=28$ birds) based on overfeeding and an "alternative" system (Alt., $n=57$ birds) (Fig. 1), and body weight (BW) at 91 days was standardized between the two systems. In the conventional system, birds were overfed from 91 to 107 days of age in housing, feeding and management conditions previously described by Arroyo et al. [20]. Birds were given a corn mixture composed of $34 \%$ of corn flour, $24 \%$ of whole corn, $40 \%$ of water, and $2 \%$ of vitamins. Birds in the alternative system were housed in a building of $73 \mathrm{~m}^{2}$ and submitted to a breeding program adapted from the protocol of Guy et al. [6] in order to mimic pre-migratory conditions. Briefly, birds were submitted to a controlled feeding period (CF) with the commercial grower-finisher diet used in the previous period ( $280 \mathrm{~g} /$ day from 91 to 133 days of age and $180 \mathrm{~g} /$ day from 133 to 161 days of age). It aimed to ensure normal 


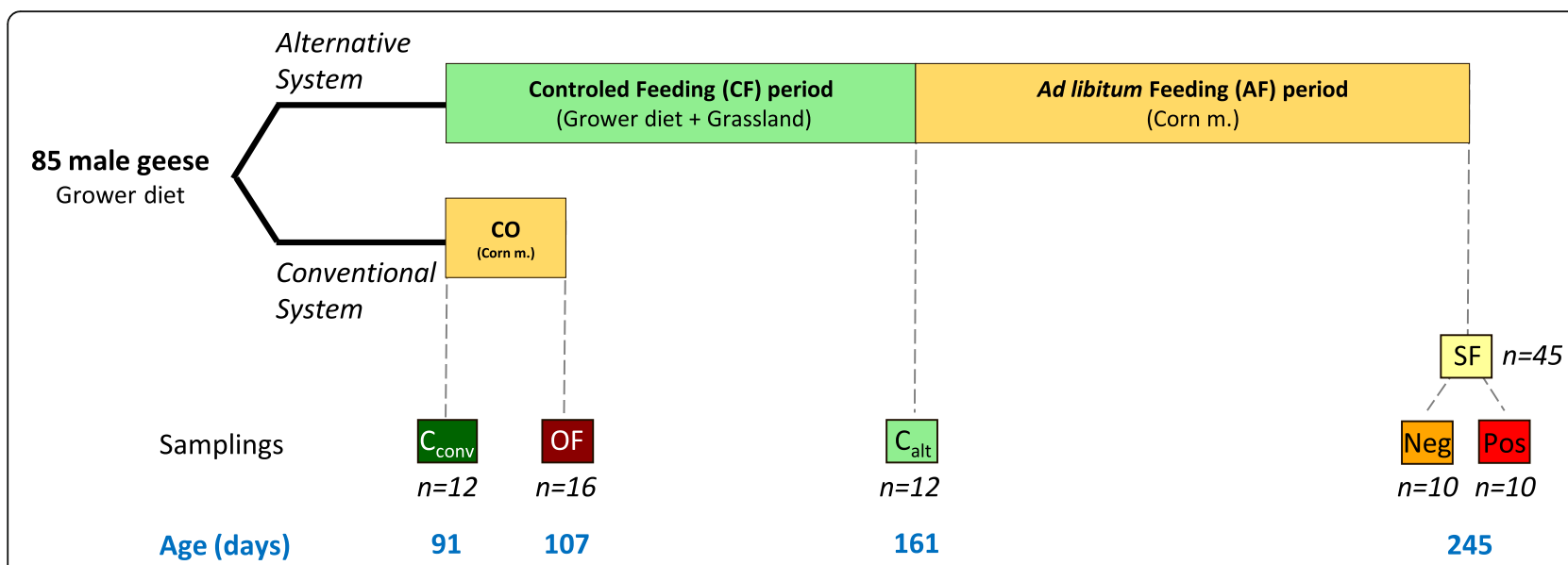

Fig. 1 Experimental design. Two steatosis induction rearing systems were studied, the conventional one using conventional overfeeding (CO) with a corn mixture (Corn m.) and an alternative one using a spontaneous steatosis stimulation alternating a controlled feeding (CF) period with a grower diet and an access to a grassland and an Ad libitum feeding (AF) period with the same corn mixture as in the conventional system. In both systems samplings were made before ( $C_{\text {conv }}$ and $C_{\text {alt }}$ groups) and after corn mixture feeding (OF and SF groups). At the end of the AF period 45 geese were sampled and the 10 animals with the highest (PosSF) and the lowest (NegSF) liver weights were selected. AF: Ad libitum feeding, C: Control, CF: Controled Feeding, CO: Conventional overfeeding, OF: Overfeeding group, SF: Spontaneous fattening groups

growth, prevent excessive fattening, increase ingestion capacity and induce hyperphagia when feed was subsequently provided ad libitum. As geese are herbivorous birds [21], in order to maintain a large crop volume and further improve the ingestion capacity, birds had free access to a grassland of $4350 \mathrm{~m}^{2}$. This was an innovation compared to previous studies on spontaneous steatosis stimulation where no access to an outdoor grassland was provided and animals were housed in a closed building from 105 days onwards $[6,9,22]$. As a result, no artificial light stimulation was performed. Birds were however submitted to the natural reduction in day length from 13h16min at 91 days of age (Early September) to $9 \mathrm{~h} 45 \mathrm{~min}$ at 161 days of age (Mid November). At the end of the CF period the access to the outdoor area was suppressed and the birds were fed freely with the same corn mixture as in the conventional system for 12 weeks (Ad libitum feeding (AF) period, 161 to 245 days of age at the end of which day length was of 9h53min (Early February)). We chose to use the corn mixture as feed in order to have equivalent diets provided to birds in both systems (Conventional vs Alternative) during steatosis induction. Ambient temperatures ranged from $+4{ }^{\circ} \mathrm{C}$ to $+16^{\circ} \mathrm{C}$ along the $\mathrm{AF}$ period and were on average of $+9^{\circ} \mathrm{C}$ (Supplemental Fig. 1).

\section{Measurements, slaughter and samplings}

Feed intake was recorded individually at each meal during overfeeding in the conventional system and per pen, daily, during the CF period and weekly during the AF period, in the alternative system. During the CF period refusals were equal to zero. Corn mixture intake is expressed in $\mathrm{g}$ of $\mathrm{DM} /$ bird (estimating $\mathrm{DM}_{\text {whole corn }}=$
0.89) while the Grower-Finisher diet intake is expressed in g/bird. Crop volume was measured before slaughter according to the procedure described by Arroyo et al. [23]. Animals were weighed at slaughter.

In both systems, birds were slaughtered before steatosis induction (91 days of age in the conventional system, " $\mathrm{C}_{\text {conv" }}$ "group, $n=12$ and at 161 days of age in the alternative system, " $\mathrm{C}_{\mathrm{alt}}$ " group, $n=12$ ) and after steatosis induction at 107 days of age, after conventional overfeeding (CO), in the conventional system (Overfed, "OF" group, $n=16$ ) and at 245 days of age, after 12 weeks of Ad libitum feeding (AF), in the alternative system (Spontaneous fattening, "SF" group, $n=45$ ) (Fig. 1). Birds were electrically stunned and immediately killed by an exsanguination through a ventral cut of neck blood vessels. The liver and abdominal fat were carefully removed and weighted. Immediately after evisceration, ileal content was sampled and stored at $-80{ }^{\circ} \mathrm{C}$ until further analyses. The right lobe of the liver was sampled, immediately frozen in liquid nitrogen and stored at $80{ }^{\circ} \mathrm{C}$ until further analyses.

In the SF group liver weight was of $158 \pm 69 \mathrm{~g}$. Two subsets of 10 geese from the SF group were generated: PosSF, the 10 geese with the highest liver weights ( $>200$ g) and NegSF, the 10 geese with the lowest liver weights $(<100 \mathrm{~g})$ (Supplemental Fig. 2A). Solely these two subsets were analyzed and will be presented for the SF group.

\section{Biochemical characterization of the livers}

Dry matter (DM) content was determined by drying grinded fresh liver samples in an oven at $105^{\circ} \mathrm{C}$ for $24 \mathrm{~h}$ and mineral matter determined after $16 \mathrm{~h}$ at $550^{\circ} \mathrm{C}$. As 
lipid contents were high, samples were mixed with fine sand to increase the exchange surface and avoid fat crust formations. Total nitrogenous matter was determined after total combustion by the Dumas method [24] using a Leco auto-analyser (FP 428; Leco Corp., St Joseph, Michigan, USA). Total lipid content was determined after cold extraction in a chloroform/methanol mixture $(2 / 1, \mathrm{~V} / \mathrm{v})$ and measured gravimetrically according to the method described by Folch et al. [25], with $1 \mathrm{~g}$ of fresh liver for $50 \mathrm{ml}$ of extraction volume. For measurements of lactate, glucose and glycogen, $2 \mathrm{~g}$ of liver were homogenized with an Ultra Turrax (IKA T-25, Fisher Scientific, Illkirch, France) in $10 \mathrm{ml}$ of $0.5 \mathrm{M}$ perchloric acid. After a $15 \mathrm{~min}$ centrifugation at $2500 \mathrm{~g}$ at $4{ }^{\circ} \mathrm{C}$, supernatants were used for glucose determination before (total glucose) and after (free glucose) hydrolyzation of glycogen with amyloglucosidase according to the method of Dalrymple and Hamm [26]. Glycogen was calculated as the difference between total and free glucose. Lactate level was determined on the same supernatants through an absorbance measurement at $340 \mathrm{~nm}$ after addition of lactate dehydrogenase, according to the method of Bergmeyer et al. [27]. Glucose, glycogen and lactate levels are expressed in $\mu \mathrm{mol}$ per gram of fresh liver.

\section{DNA extractions, 16S rRNA gene sequencing and sequence analysis}

Ileal content DNA was extracted combining mechanical, chemical and thermic lysis with an Ultra Turrax Digital Homogenizer (IKA T-25, Fisher Scientific, Illkirch, FR) and the QIAamp Fast DNA Stool Mini Kit (Qiagen Gmbh, Hilden, DE) according to the manufacturer's instructions. Quantity and quality of extracted DNA were determined with a NanoVue Plus Spectrophotometer (GE Healthcare, Vélizy-Villacoublay, FR). The V3-V4 regions of $16 \mathrm{~S}$ rRNA genes were amplified by PCR and sequenced by MiSeq Illumina Sequencing at the Genomic and Transcriptomic Platform (GeT-PlaGe, INRAE, Toulouse, France).

16S rRNA gene amplicon sequences were analyzed using the FROGS pipeline according to standard operating procedures [28]. Only amplicons with size between 380 and $500 \mathrm{bp}$, without ambiguous bases and with the two primers were kept. Due to low number of reads one sample of the $C_{\text {alt }}$ group (2236 reads) and one of the NegSF group (3040 reads) were excluded from further analyses. Sequences were clustered $(d=1+d=3)$ using Swarm and chimeras were removed. The remaining clusters were filtered. Clusters that were present in at least 7 samples and with abundances greater than $0.005 \%$ of total sequences [29] were kept as OTUs (operational taxonomic units). Taxonomic affiliation of OTUs was obtained using the Silva132 database with a minimum pintail quality of 80 [30]. Samples had on average 28,015 \pm 8698 reads (min: 5586, max: 46184) with 266 OTUs represented ( $98 \pm 28$ OTUs per sample).

\section{Statistical analyses}

Statistical analyses were performed using R software version 4.0.2. The microbial composition was analysed with the phyloseq package [31]. For alpha and beta diversity analyses, samples were rarified to even depth (5586 reads). Beta-diversity was determined using the BrayCurtis dissimilarity method and plotted by non-Metric Dimensional Scaling (nMDS) ordination method. To assess group differences an ADONIS pairwise test with the Bray-Curtis distance was carried out. A Partial Least Squares Discriminant Analyzis (PLS-DA) was performed to determine the most discriminant OTUs separating NegSF and PosSF geese using the $\mathrm{R}$ mixOmics package [32]. Taxa differential abundance analyses and PLS-DA were performed on unrarefied data with OTUs with abundances above $0.1 \%$ of total sequences in at least one experimental group, which was considered as a quantitative threshold.

Growth and slaughter performances, biochemical parameters, microbial alpha diversity and relative abundances at phylum, family, genus and OTU levels were analysed using a non-parametric Kruskal-Wallis test with the experimental group as factor. When significant $(P<0.05)$, groups were compared pairwise with a Wilcoxon test. For taxa relative abundances $p$-values were adjusted for multiple tests with the false discovery rate (FDR) method.

\section{Results}

\section{Growth, intake and performances at slaughter}

In the conventional system, feed intake averaged $742 \pm$ $239 \mathrm{~g} \mathrm{DM} / \mathrm{bird} /$ day for a total of $11,873 \mathrm{~g} \mathrm{DM} /$ bird during the whole overfeeding period (91 to 107 days of age, Fig. 2). No variability was observed between animals as they all had the same meals (frequency and amount distributed). In the alternative system no refusals were observed during the Controlled Feeding (CF) period, and average pellet intakes were of $280 \mathrm{~g} / \mathrm{bird} /$ day until 133 days of age and $180 \mathrm{~g} / \mathrm{bird} /$ day from 133 to 161 days of age. Grass intake was not measured. In the alternative system, although grazing during the CF period was intended to increase crop volume, no difference was observed when comparing $\mathrm{C}_{\text {conv }}$ and $\mathrm{C}_{\text {alt }}$ birds (Table 1). During the AF period (161 to 245 days of age) feed intake averaged $268 \mathrm{~g} \mathrm{DM/bird/day} \mathrm{(Fig.} \mathrm{2).} \mathrm{Total} \mathrm{feed} \mathrm{in-}$ take over the 12 weeks of AF was of 23,050 g DM/bird (almost 2 fold the consumption in the conventional system during the 16 days of overfeeding).

As expected, in the conventional system, OF birds (107 days of age) had a higher BW $(+52 \%, P<0.001)$ 


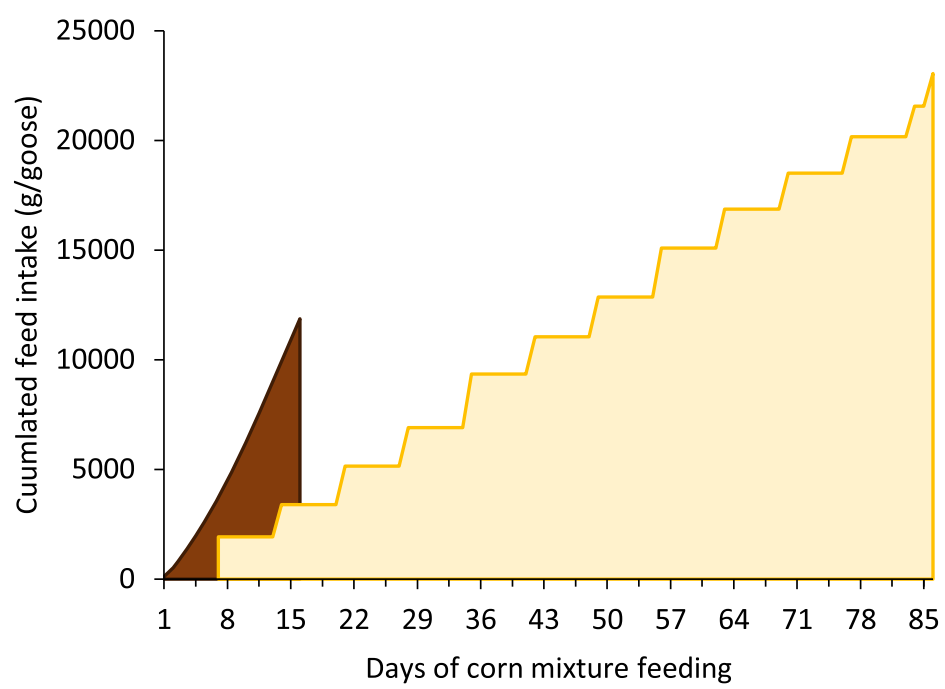

Conventional

$\square$ Alternative

Fig. 2 Cumulated feed intake during the corn mixture feeding periods (CO during 16 days in the Conventional system and AF during 12 weeks in the alternative system). Feed intake is expressed in equivalent of dry matter. Intake was measured daily in the conventional system and weekly in the alternative system

Table 1 Growth and slaughter performances and chemical composition of the livers according to the experimental group

\begin{tabular}{|c|c|c|c|c|c|c|}
\hline & \multicolumn{2}{|c|}{ Conventional } & \multicolumn{3}{|l|}{ Alternative } & \multirow[t]{2}{*}{$P$} \\
\hline & $\begin{array}{l}C_{\text {conv }} \\
(n=12)\end{array}$ & $\begin{array}{l}\text { OF } \\
(n=16)\end{array}$ & $\begin{array}{l}\mathrm{C}_{\mathrm{alt}} \\
(n=11)\end{array}$ & $\begin{array}{l}\text { NegSF } \\
(n=9)\end{array}$ & $\begin{array}{l}\text { PosSF } \\
(n=10)\end{array}$ & \\
\hline \multicolumn{7}{|c|}{ Growth and slaughter performances } \\
\hline BW (g) & $5279 \pm 462^{a}$ & $8014 \pm 424^{b}$ & $5589 \pm 543^{a}$ & $6267 \pm 502^{c}$ & $8835 \pm 858^{d}$ & $* * *$ \\
\hline Liver (g) & $149 \pm 22^{a}$ & $990 \pm 213^{b}$ & $126 \pm 17^{c}$ & $98 \pm 10^{d}$ & $269 \pm 56^{e}$ & *** \\
\hline$\% B W$ & $2.8 \pm 0.3^{a}$ & $12.4 \pm 2.9^{b}$ & $2.3 \pm 0.4^{c}$ & $1.6 \pm 0.1^{d}$ & $3.0 \pm 0.4^{a}$ & *** \\
\hline Abdominal fat (g) & $112 \pm 39^{a}$ & ND & $76 \pm 25^{b}$ & $236 \pm 51^{c}$ & $630 \pm 108^{d}$ & *** \\
\hline$\% B W$ & $2.1 \pm 0.8^{a}$ & ND & $1.4 \pm 0.5^{b}$ & $3.8 \pm 0.7$ & $7.1 \pm 1.0^{d}$ & *** \\
\hline Crop volume (mL) & $306 \pm 65$ & ND & $264 \pm 54$ & $279 \pm 70$ & $249 \pm 66$ & NS \\
\hline \multicolumn{7}{|c|}{ Chemical composition of the liver } \\
\hline DM (\%) & $31.0 \pm 1.3^{\mathrm{a}}$ & $64.8 \pm 3.5^{\mathrm{b}}$ & $31.7 \pm 1.4^{\mathrm{a}}$ & $31.0 \pm 1.1^{\mathrm{a}}$ & $46.5 \pm 6.7^{c}$ & *** \\
\hline MM (\%) & $1.1 \pm 0.1^{\mathrm{a}}$ & $0.4 \pm 0.1^{b}$ & $1.1 \pm 0.1^{\mathrm{ac}}$ & $1.0 \pm 0.1^{c}$ & $0.6 \pm 0.2^{d}$ & $* * *$ \\
\hline Lipids (\%) & $4.5 \pm 0.8^{\mathrm{a}}$ & $53.9 \pm 4.9^{b}$ & $4.6 \pm 0.5^{\mathrm{a}}$ & $5.3 \pm 0.6^{c}$ & $26.8 \pm 9.5^{d}$ & $* * *$ \\
\hline Total nitrogen (\%) & $16.1 \pm 1.9^{\mathrm{a}}$ & $8.0 \pm 1.6^{b}$ & $15.4 \pm 1.5^{\mathrm{a}}$ & $18.1 \pm 2.1^{c}$ & $12.6 \pm 2.0^{d}$ & *** \\
\hline Total glucose $(\mu \mathrm{mol} / \mathrm{g})$ & $633 \pm 134^{a}$ & $86 \pm 27^{b}$ & $607 \pm 116^{\mathrm{ac}}$ & $459 \pm 125^{c d}$ & $380 \pm 97^{d}$ & *** \\
\hline$\mu \mathrm{mol} / \mathrm{g}$ fat free liver & $605 \pm 127^{a}$ & $40 \pm 17^{b}$ & $579 \pm 111^{a c}$ & $434 \pm 117^{c d}$ & $285 \pm 97^{d}$ & *** \\
\hline Free glucose $(\mu \mathrm{mol} / \mathrm{g})$ & $70 \pm 11^{\mathrm{a}}$ & $34 \pm 7^{b}$ & $47 \pm 7^{c}$ & $84 \pm 10^{d}$ & $51 \pm 9^{c}$ & *** \\
\hline$\mu m o l / g$ fat free liver & $67 \pm 11^{a}$ & $16 \pm 4^{b}$ & $45 \pm 6^{c}$ & $80 \pm 10^{d}$ & $38 \pm 10^{c}$ & $* * *$ \\
\hline Glycogen $(\mu \mathrm{mol} / \mathrm{g})$ & $563 \pm 135^{a}$ & $51 \pm 27^{b}$ & $560 \pm 113^{a}$ & $375 \pm 130^{c}$ & $328 \pm 93^{c}$ & $* * *$ \\
\hline $\mu$ mol/g fat free liver & $538 \pm 128^{a}$ & $25 \pm 16^{b}$ & $534 \pm 108^{a}$ & $355 \pm 123^{c}$ & $247 \pm 89^{c}$ & $* * *$ \\
\hline Lactate $(\mu \mathrm{mol} / \mathrm{g})$ & $6.9 \pm 1.5^{\mathrm{a}}$ & $9.6 \pm 2.0^{\mathrm{bc}}$ & $6.7 \pm 0.8^{\mathrm{a}}$ & $10.5 \pm 0.8^{b}$ & $8.0 \pm 1.5^{\mathrm{ac}}$ & *** \\
\hline$\mu \mathrm{mol} / \mathrm{g}$ fat free liver & $6.6 \pm 1.5^{a}$ & $4.4 \pm .01^{b}$ & $6.4 \pm 0.8^{a}$ & $10.0 \pm 0.7^{c}$ & $5.8 \pm 1.4^{a}$ & $* * *$ \\
\hline
\end{tabular}

Values are presented as Mean \pm SD

$\mathrm{C}_{\text {conv }}$ Control group before overfeeding, OF Overfed group, $C_{\text {alt }}$ Control group before Ad libitum corn mixture feeding, NegSF Negative response group to spontaneous fattening induction, PosSF Positive response group to spontaneous fattening induction, BW Body Weight, DM Dry Matter, MM Mineral Matter, ND Not Determined

*** $P<0.001$, NS Not Significant

Means within a row with different superscripts differ significantly $(P<0.05)$ 
with an increased liver proportion (+ 9.6 pts., $P<0.001$ ) compared to controls before overfeeding $\left(C_{\text {conv }}, 91\right.$ days of age) (Table 1). Similarly, in the alternative system, SF birds (245 days of age), regardless of response to steatosis induction, had a higher BW $(6267 \pm 502 \mathrm{~g}$ for the NegSF group and $8835 \pm 858 \mathrm{~g}$ for the PosSF group, $P<$ $0.05)$ compared to controls before the AF period $\left(C_{\text {alt }}\right.$, 161 days of age, $5589 \pm 517 \mathrm{~g}$ ). The proportion of the liver was slightly decreased in the NegSF group and increased in the PosSF group compared to $\mathrm{C}_{\text {alt }}$ birds (respectively $1.6 \pm 0.1$ and $3.0 \pm 0.4$ vs $2.3 \pm 0.4 \%, P<0.05$ ) while that of abdominal fat increased strongly in both SF groups $(3.8 \pm 0.7 \%$ in the NegSF group and $7.1 \pm 1 \%$ in the PosSF group vs $1.3 \pm 0.5 \%, P<0.001)$. After steatosis induction, liver proportion $(-10.8$ pts. for the NegSF group and -9.4 pts. for the PosSF group, $P<0.001$ ) was significantly lower in the alternative system compared to the conventional one and body weight was reduced in the NegSF group $(-21 \%, P<0.001)$ while it was increased in the PosSF group $(+10 \%, P<0.05)$ compared to the OF group. In the alternative system, BW $(+41 \%$, $P<0.001)$, liver proportion $(+1.4$ pts., $P<0.001)$ and abdominal fat proportion $(+3.3$ pts., $P<0.001)$ were, as expected, higher in the PosSF group compared to the NegSF group (Table 1 and Supplemental Fig. 2A-B).

\section{Liver biochemical results}

As expected, in the conventional system, the higher liver weight observed in OF birds compared to controls $\left(\mathrm{C}_{\text {conv }}\right)$ was associated with an increase in liver lipid content $(+49$ pts., $P<0.001)$ and lactate level $(+39 \%, P<$ $0.01)$ and a decrease in glycogen $(-91 \%, P<0.001)$, free glucose $(-51 \%, P<0.001)$ and nitrogen $(-8$ pts., $P<0.001$ ) levels (Table 1 ).

In the alternative system, liver lipid content was higher in both SF groups compared to controls $\left(\mathrm{C}_{\text {alt }}\right)$ and this difference was greater in the PosSF group $(+22.2$ pts., $P<0.001$ vs $+0.7, P<0.05$ for the NegSF group). Conversely, glycogen levels were lower in both SF groups compared to controls $\left(C_{\text {alt }}\right)(-33 \%, P<0.05$ for the NegSF group and $-42 \%, P<0.001$ for the PosSF group) with no significant difference between NegSF and PosSF groups. Free glucose and lactate levels were increased in the NegSF group compared to controls $\left(C_{\text {alt }}\right)(+79 \%$, $P<0.001$ and $+57 \%, P<0.001$ respectively) while no significant difference was observed between the PosSF and $\mathrm{C}_{\text {alt }}$ groups. Compared to controls $\left(\mathrm{C}_{\text {alt }}\right)$, nitrogen levels were increased in the NegSF group $(+2.7$ pts, $P<0.01)$ and decreased in the PosSF group $(-2.8$ pts., $P<0.01)$.

When comparing both systems after steatosis induction, lipid levels $(P<0.001)$ were lower in the alternative system compared to the conventional one while free glucose $(P<0.001)$, glycogen $(P<0.001)$ and nitrogen $(P<0.001)$ levels were higher, regardless of the response to SF. Only lactate levels were unaffected by the breeding system, although when expressed in proportion of the fat free liver weight lactate levels were increased in the alternative system compared to the conventional one regardless of the response to SF $(P<0.05)$.

\section{lleal bacterial community}

Steatosis induction did not alter alpha diversity in the conventional system. In the alternative system the observed number of OTUs was altered in the NegSF group compared to $C_{\text {alt }}$ birds $(P<0.05)$. All other diversity indices were unaffected (Fig. 3a). When comparing both systems, the observed number of OTUs was reduced in the NegSF group compared to the OF group $(P<0.05)$. Regarding beta-diversity all experimental groups could clearly be distinguished using the Bray-Curtis dissimilarity method and Adonis pairwise tests, except the two SF groups that were similar (Fig. 3b-c, Supplemental Table 1). In both systems, steatosis induction (OF and $\mathrm{SF}$ ) resulted in variations in beta-diversity compared to their respective controls $\left(C_{\text {conv }}\right.$ with $\mathrm{R} 2$-Adonis of 0.23 , $P<0.01$ and $C_{\text {alt }}$ R2-Adonis ranging between 0.29 and $0.3, P<0.01)$. When comparing steatosis induction modes OF birds differed from NegSF (R2-Adonis of $0.25, P<0.01$ ) and PosSF (R2-Adonis of $0.21, P<0.01$ ) birds. No differences in beta-diversity were observed between birds with different aptitudes to spontaneous steatosis (NegSF vs PosSF). In order to evaluate whether some bacterial taxa could distinguish these two groups a PLS-DA analysis was performed keeping OTUs with abundances above $0.1 \%$ in at least one of the two groups (Fig. 4a-b). A separation was obtained and the top 10 most contributing OTUs were identified. Among those, OTU48 (Lactobacillus sp.) was differentially represented in PosSF and NegSF groups in univariate analyses ( 0.2 vs $0 \%$ in the NegSF group, $P=0.01$ ) (Fig. 4c, Supplemental Table 2).

When performing taxonomic affiliations on OTUs with abundances above $0.1 \%$ in at least one experimental group 6 phyla, 31 families and 52 genera were observed in the overall dataset. Results are presented at phylum (Fig. 5a-b; Supplemental Table 3), family (Fig. 5c-d; Supplemental Table 4) and genus levels (Fig. 5e-f; Supplemental Table 5). Firmicutes and Proteobacteria were the most abundant phyla with Lactobacillaceae and Peptostreptococcaceae of the first mentioned phylum being the most abundant families.

In the conventional system, the proportions of Epsilonbacteraeota $(-12.3$ pts., $P<0.05)$ and its sole genus Helicobacter from the dominant family Helicobacteraceae were lower after steatosis induction (OF) compared to $\mathrm{C}_{\text {conv }}$ birds while the proportion of Proteobacteria was not significantly modulated but the proportions of two of its dominant families, Burkholderiaceae and 


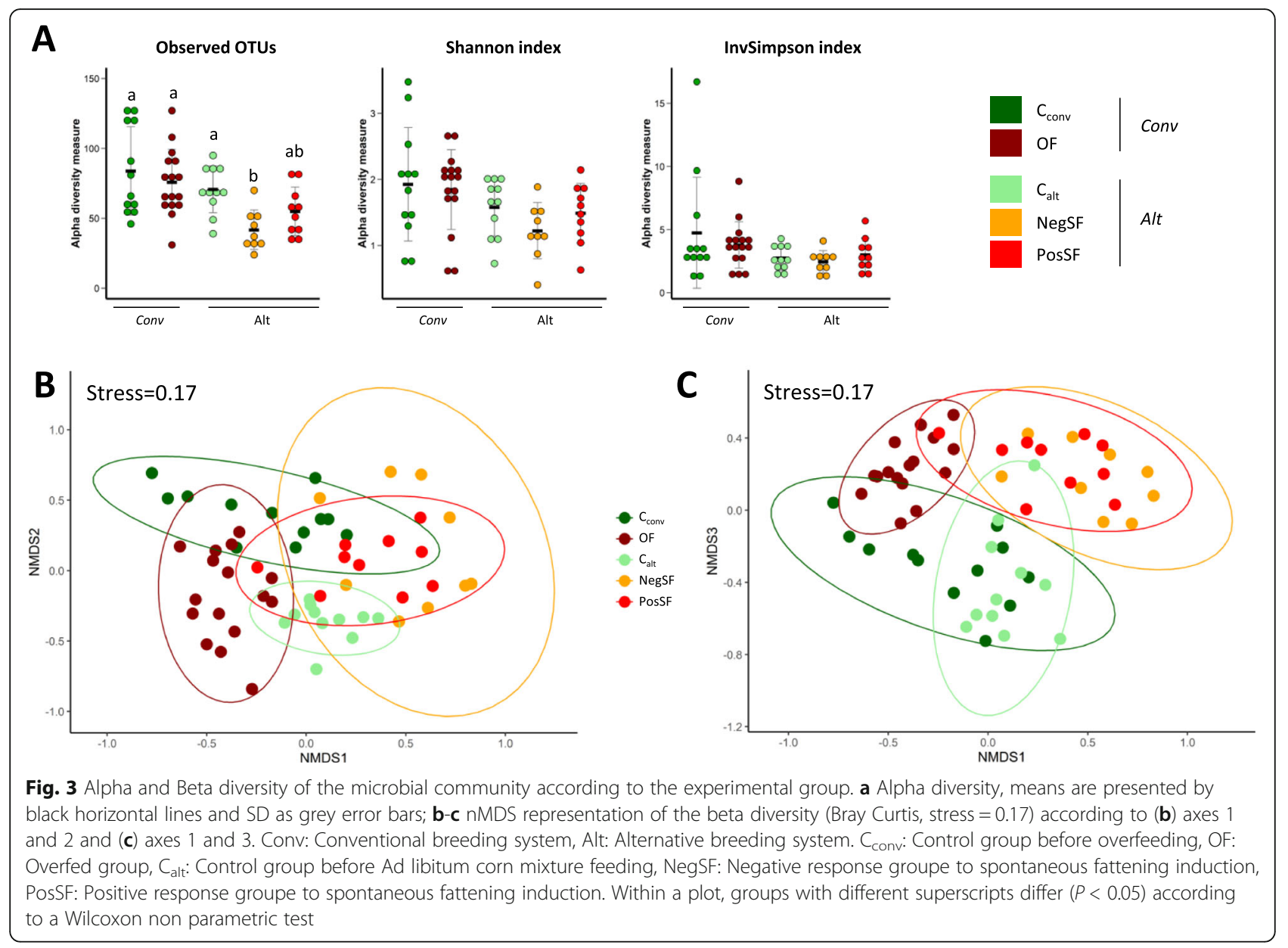

Sphingomonadaceae, were significantly increased $(+20.8$ pts., $P<0.01$ and +12.7 pts., $P<0.01$ respectively). These increases were attributable to that of the main genera of aforementioned families, Ralstonia $(+18.5$ pts., $P<0.01$ ) and Sphingomonas (+ 12.7 pts., $P<0.01$ ) respectively.

In the alternative system, the proportion of Fusobacteria was higher after steatosis induction compared to $C_{\text {alt }}$ birds regardless of the steatosis level $(+6.3$ pts., $P<0.01$ in the NegSF group and +0.2 pts., $P<0.001$ in the PosSF group) reflecting the levels of its sole representative genus Fusobacterium of the Fusobacteriaceae family. The proportion of Firmicutes was unaffected, but that of its two main families was modulated with the proportion of Peptostreptococcaceae being drastically increased after steatosis induction compared to $C_{\text {alt }}$ birds regardless of steatosis level $(+40.2$ pts., $P<0.01$ for the NegSF group and +45.6 pts., $P<0.01$ for the PosSF group) while the level of Lactobacillaceae decreased solely in the PosSF group $(-41.6$ pts., $P<0.01)$ reflecting the decrease in its main genus Lactobacillus (- 41.5 pts., $P<0.01)$. Although the proportion of Proteobacteria was unaffected by steatosis induction, that of one of its main families, Sphingomonadaceae, decreased solely in the
NegSF group as a result of the decrease of its sole genus Sphingomonas $(-4.0$ pts., $P<0.05)$.

Regardless of the taxonomic rank considered (phylum, family and genus) no significant differences were observed between animals differing in aptitudes to spontaneous steatosis (NegSF vs PosSF).

When comparing systems after steatosis induction, SF birds had consistently higher levels of Fusobacteria compared to the OF birds $(+6.3$ pts., $P<0.01$ for the NegSF group and +0.2 pts., $P<0.001$ for the PosSF group). The level of Proteobacteria was lower only in the NegSF group $(-32.8$ pts., $P<0.05)$ as a result of the decrease in proportion of its two main families, Burkholderiaceae and Sphingomonadaceae $(-20.3$ pts., $P<0.01$ and -11.7 pts., $P<.0 .01$ respectively), the PosSF group having intermediate values. These decreases were attributable to the decreases in the main genera of the aforementioned families, Ralstonia ( -17.9 pts., $P<0.01$ ) and Sphingomonas $(-11.7$ pts., $P<0.01)$ respectively. The level of Epsilonbacteraeota was higher only in the PosSF group (+ 10.6 pts., $P<0.05)$ although the level of the sole representative genus, Helicobacter, of its main family Helicobacteraceae was greater in both SF groups (+ 12.3 pts., 


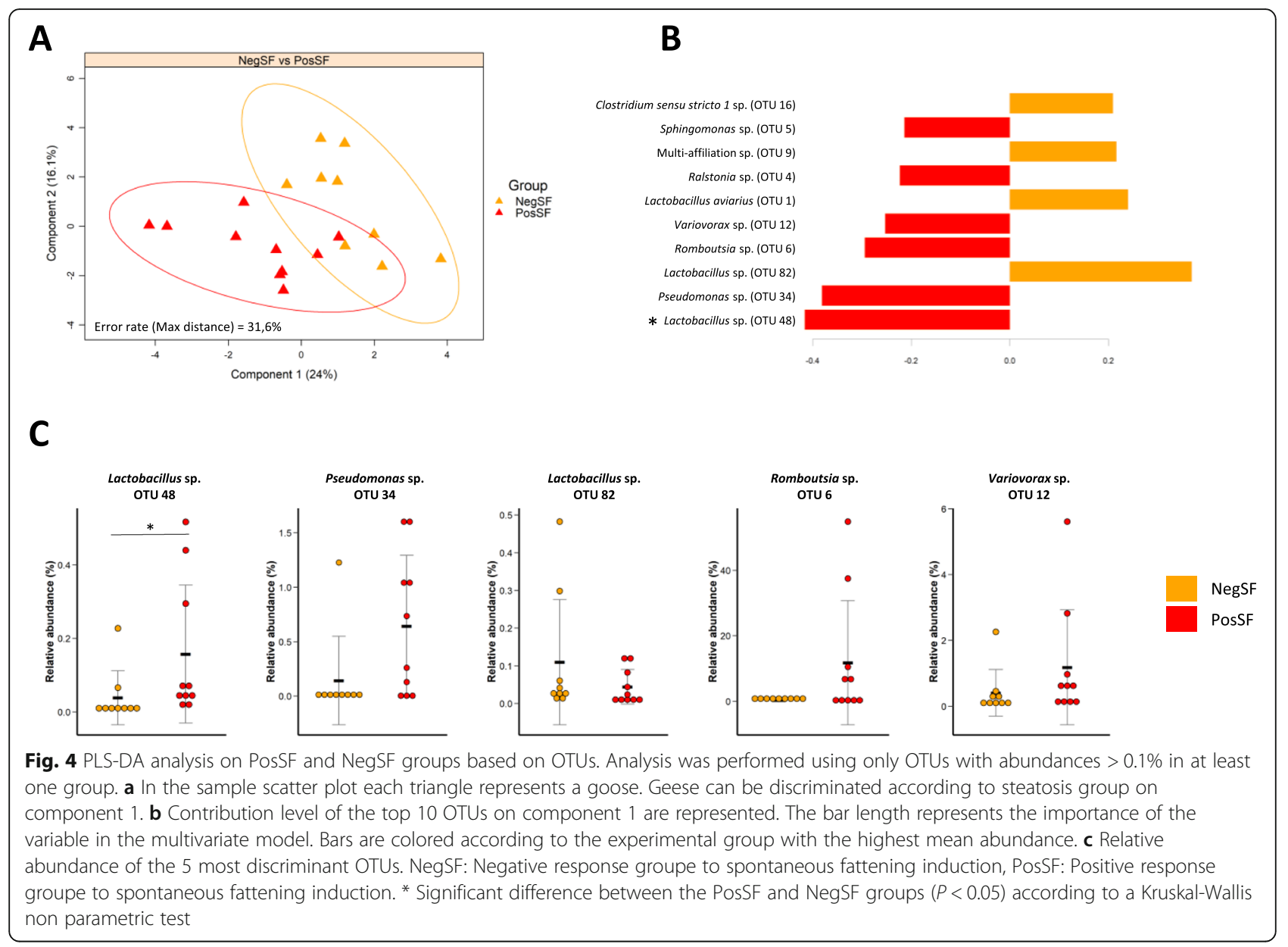

$P<0.05$ for the NegSF group and +10.7 pts., $P<0.05$ for the PosSF group). Firmicutes were unaffected by breeding system, although the level of one of its main families, Peptostreptococcaceae, was consistently higher compared to the OF birds $(+38.4$ pts., $P<0.01$ for the NegSF group and +43.8 pts., $P<0.01$ for the PosSF group).

\section{Discussion}

Conventional overfeeding in waterfowl is today questioned for animal welfare reasons. Although spontaneous steatosis has been experimentally induced in greylag geese, great variability has been observed in both feed intake and steatosis level $[6,9]$. Feed intake is the main contributor to steatosis, but other factors such as the digestive microbiota could also be involved. The present study thus aimed to address two issues: (i) evaluate whether microbial composition differed with steatosisinducing mode; (ii) elucidate whether a digestive microbial signature could be associated with different aptitudes to spontaneous liver steatosis.
Biochemical composition of the livers and microbiota differed considerably in response to the steatosis induction systems, the conventional one, based on overfeeding, and the alternative one, based on a spontaneous ad libitum feeding, although birds were given the same diet during the steatosis induction period. The alternative steatosis inducing system led to an $84 \%$ lower liver weight than in the conventional steatosis inducing system, mainly due to a considerably lower daily feed intake (-64\%), although feed intake on the overall corn mixture feeding period was almost doubled in the alternative system as previously reported [8]. The increase in liver weight observed in birds with a positive response to spontaneous steatosis stimulation was partly linked to an increased lipogenesis, as observed to a greater extent in the overfed birds. Indeed, regardless of the type of steatosis induction, a decrease in glycogen concentration associated with an increased liver lipid content were observed as previously described in overfed ducks [33]. Furthermore, lipid storage in adipose tissues (appreciated through the variations in abdominal fat weight) strongly increased in birds developing a spontaneous 
A

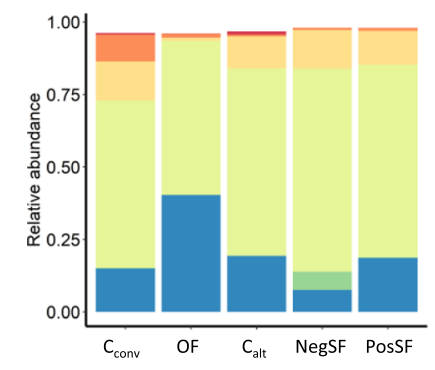

C

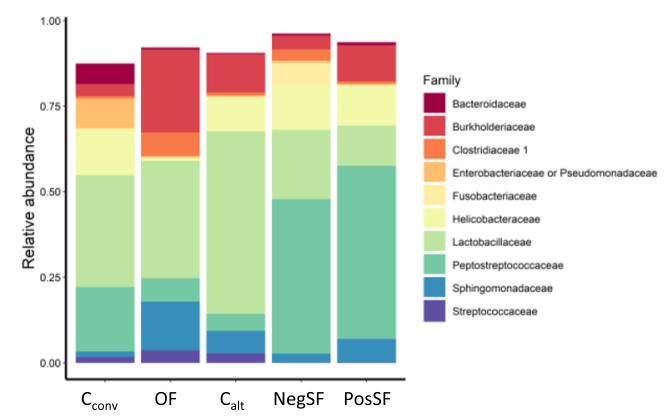

B
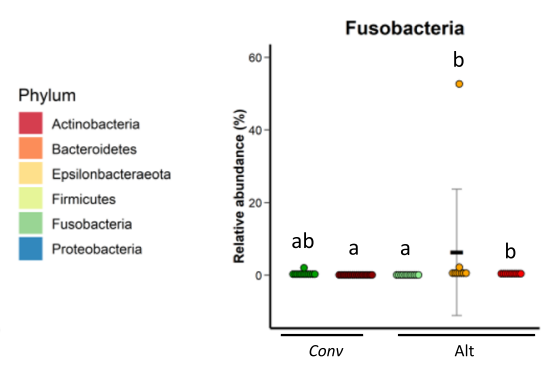
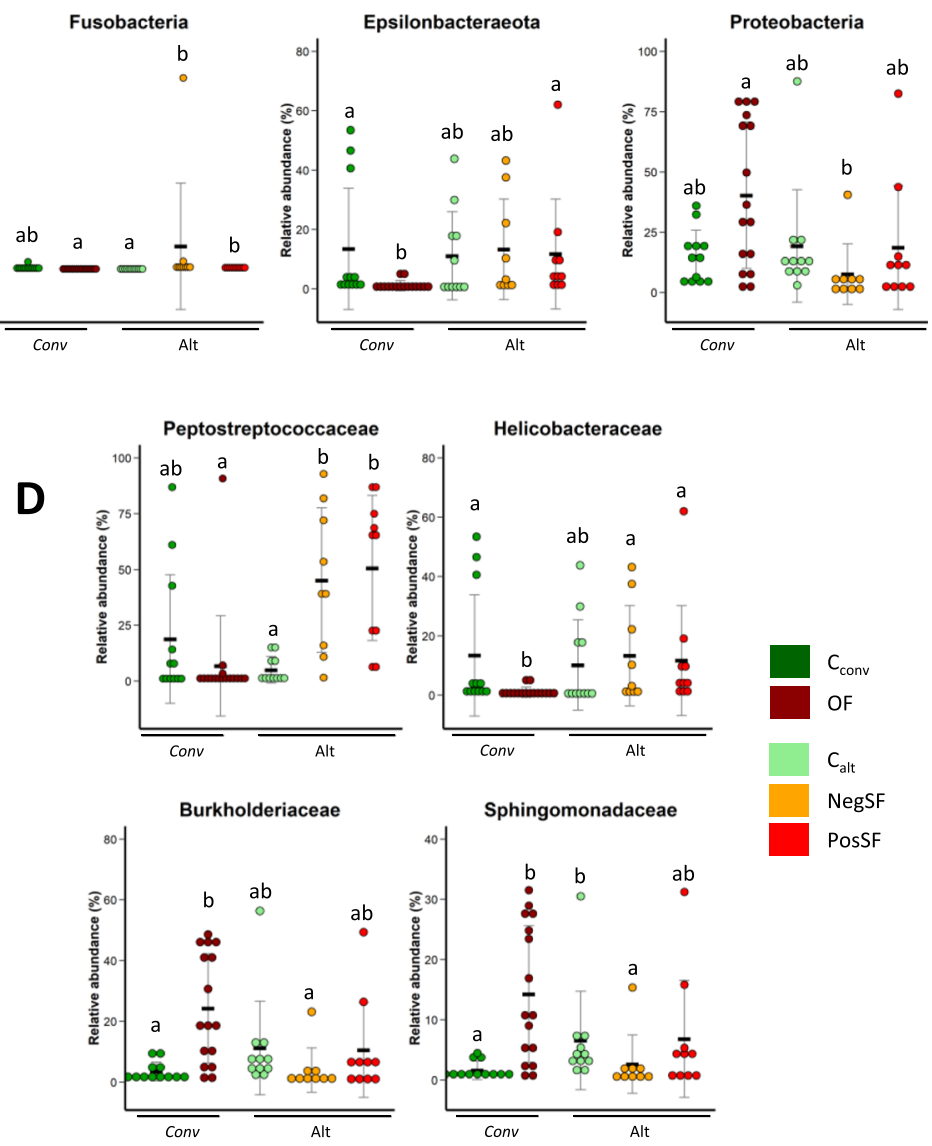

E

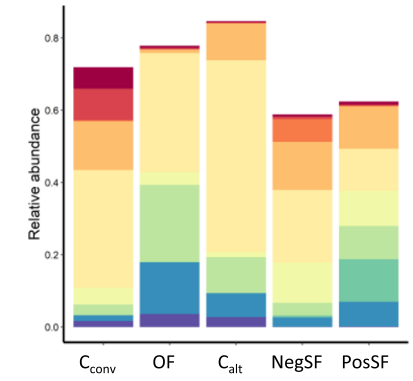

$\mathbf{F}$

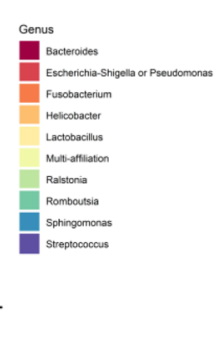

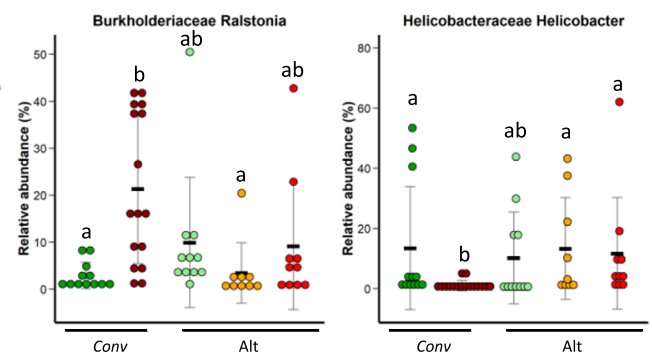

Fig. 5 Microbial composition according to the experimental groups at (a-b) Phylum, (c-d) Family and (e-f) Genus level. In panels (c) and (e) only the 10 most abundant Families (c) and Genera (e) are depicted. Means are presented by black horizontal lines and SD as grey error bars. Conv: Conventional breeding system, Alt: Alternative breeding system. $C_{\text {conv }}$ : Control group before overfeeding, OF: Overfed group, $C_{\text {alt: }}$ Control group before Ad libitum corn mixture feeding, NegSF: Negative response groupe to spontaneous fattening induction, PosSF: Positive response groupe to spontaneous fattening induction. Within a plot, groups with different superscripts differ $(P<0.05)$ according to a Wilcoxon non parametric test

steatosis (7.1\% of BW), surpassing levels commonly observed with conventional overfeeding $(4.7-5.7 \%)$ [7, 17, 34]. This could indicate a preferential storage of lipids in these sites before, when saturated, storing in the liver.

As previously described in domesticated geese [15, 35-37], and in birds in general [38], Firmicutes and Proteobacteria ( $>70 \%$ of sequences in all groups) were the two main phyla in the Greylag goose (Anser anser) ileal microbiota. Microbial composition did however strongly differ according to the steatosis induction system.

In the conventional overfeeding system we described a drastic decrease in Helicobacter (-12.4 Pts) counterbalanced by an increase in Ralstonia (+18.5 pts) and Sphingomonas (+ 12.7 pts) after overfeeding. Previous studies emphasized an increase in the abundance of Lactobacillus in the ileum of overfed ducks [12, 13]. In 
our study, we were unable to evidence such an increase and no difference was observed between steatosis inducing systems. This might be due to the higher abundance of the Lactobacillus genus in the control groups (in comparison to previous work). However, our results are consistent with those of Liu et al. [15] who showed that, in geese, overfeeding increased the abundance of Lactobacillus in the duodenum, jejunum and ceca but not in the ileum. Lactobacillus levels might be modulated by overfeeding in geese, but not in the same intestinal segments as in ducks. It would be of interest to evaluate the impact of steatosis induction mode on the microbial composition in the different segments of the digestive tract. In the alternative system, the main variations concerned the Peptostreptococcaceae family whose proportion was drastically increased after steatosis induction regardless of steatosis level $(+40.2$ to $+45.6 \mathrm{pts})$ while the level of Lactobacillus decreased solely in birds with a positive response to spontaneous steatosis stimulation $(-41.5 \mathrm{pts})$. These results are the first to examine the microbial response to spontaneous steatosis stimulation in greylag geese.

In the present study, the major effect of steatosis induction mode on the microbiota relies on the notably higher levels of Romboutsia (Peptostreptococcaceae) in birds with a positive response to spontaneous steatosis stimulation compared to overfed birds while levels of Ralstonia, Variovorax (Burkholderiaceae) and Sphingomonas (Sphingomonadaceae) were reduced only in the birds with a negative response to spontaneous steatosis stimulation compared to overfed birds; birds with a positive response to spontaneous steatosis stimulation having intermediate values. Previous studies in geese [15] and ducks [12, 13] did not highlight changes in the abundance of these genera with steatosis induced by overfeeding even though great differences relative to controls were observed in our study. In other species little data is available on the association between these genera and lipid metabolism, steatosis and obesity. Several studies evidence increases in Romboutsia levels with obesity related metabolic disorders in humans [39] and in mice fed high fat [40] or high starch [41] diets, although no causal link has been established between this genus and obesity related traits to date. At first glance our results are in contrast with previous ones as Romboutsia levels are higher in birds with a positive response to spontaneous steatosis stimulation compared to overfed ones, despite a lower liver weight. Great metabolic changes are however susceptible to occur in birds with a positive response to spontaneous steatosis stimulation, with, as previously mentioned, a higher abdominal fat proportion compared to levels classically observed with overfeeding $(7.1 \%$ vs $4.7-5.7 \%)$ [7, 17, 34]. It would then be of interest to further evaluate these metabolic changes and their associations with the gut microbiota, notably the Romboutsia genus. Interestingly, a recent study evidenced that the fecal abundance of Ralstonia picketti was increased in obese humans with prediabetes or type 2 diabetes and that a causal association between this species and impaired glucose tolerance in dietary induced obese mice could be assessed [42]. However, in the present study, OTUs belonging to the Ralstonia genus were not affiliated to a sole distinct species. Another recent study also evidenced correlations between the plasmatic levels of Variovorax and Sphingomonas and liver fibrosis in obese patients [43]. These correlations were not observed when examining the fecal microbiota. It is also to be noted that the level of Proteobacteria - phylum to which Ralstonia, Variovorax and Sphingomonas belong - is consistently higher in steatosis and non-alcoholic steatohepatitis (NASH) patients [44] compared to controls. Although hepatic metabolism differs greatly between birds and mammals it would be of interest to further evaluate the causal link between Ralstonia, Variovorax and Sphingomonas and steatosis in waterfowl.

The discrepancies between steatosis stimulation systems could be explained by five factors inherent to the two systems: the age, the type of feed ingested prior to the steatosis induction period, the daily feed intake during steatosis induction, the duration of the steatosis induction period, the extent of the induced-steatosis and/ or a combination of these factors. It is well documented that microbial composition changes with age in the early life in all species, including birds $[45,46]$. In ducks the microbial composition stabilizes between 65 and 84 days of age [47]. Similar trends could be hypothesized in geese. In that context, its impact during the steatosis induction periods would be minimal. Comparing animals fed a pellet diet or fed by grazing on a pasture, $\mathrm{Xu}$ et al. [48] evidenced major changes in microbial composition at cecal level, with an increase in Firmicutes and a decrease in Bacteroidetes associated with an increased richness diversity index with grazing. However, Guo et al. [49] did not evidence any changes in cecal alphadiversity or abundances at phylum level with increased grass inclusion in the diet. Furthermore, no data are available on the impact of prior grass ingestion when the diet is changed. Altogether, it is difficult to evaluate whether the access to a pasture prior spontaneous steatosis induction would affect microbial composition. Moreover, long term feeding with the same diet can potentially affect microbial diversity. Studies in goats showed that richness decreased with long term vs short term feeding of a high concentrate diet [50]. The duration of the corn mixture feeding could have affected ilea microbial composition in the geese. Finally, regarding the feed intake, studies in mammals and birds have 
shown that feed restriction can also modulate the intestinal microbiota [51-53]. Therefore, it is possible that an increase in feed intake might influence the microbial composition as well. Altogether, considering available data in the literature, it seems worthwhile to further study the evolution of the microbiota during the first days of induction in order to determine the effect of the amount of feed ingested and the duration of the steatosis induction upon the microbial composition.

In the alternative system, after 12 weeks of spontaneous corn mixture feeding, the birds with the smallest livers were also the ones with the least subcutaneous fat, demonstrating a reduced fattening of those animals at a global scale. The absence of increase in liver weight in the birds with a negative response to spontaneous steatosis stimulation, despite an apparent metabolic reorientation, may be due to (i) a lower feed intake of those animals as previously observed by Fernandez et al. [9] and/or (ii) a reduced feed efficiency, associated with differences in microbial composition as observed in pigs and chicken [54-56]. In mice, Le Roy et al. [57] evidenced a causal link between microbial composition and steatosis onset under high fat diet feeding after inoculation of the microbiota of donor mice having developed or not a steatosis themselves. Although no causal association has been described to date in birds, a correlation between microbiota and steatosis severity (Fatty liver hemorrhagic Syndrome) has been observed in chicken [58]. However, in our study when comparing geese differing in steatosis level after 12 weeks of spontaneous corn mixture feeding no microbial signature distinguishing them was evidenced. These results could indicate that the differences in aptitudes to spontaneous steatosis in geese are mainly dependent on feed intake and host intrinsic parameters such as genetics. However, one low abundant OTU affiliated to Lactobacillus sp., discriminating the two steatosis response groups in PLS-DA analysis, was more abundant in birds having developed a spontaneous steatosis compared to those that hadn't. Interestingly, the Lactobacillus genus has been associated with steatosis in overfed ducks $[12,13]$. It would be of interest to further evaluate the associations between steatosis and species belonging to the Lactobacillus genus.

Compared to previous studies on spontaneous steatosis induction after 12 to 13 weeks of corn feeding, liver weights were overall lower in our experiment ( $158 \mathrm{~g}$ vs $>440 \mathrm{~g}$ ) [6, 9, 17]. On the overall corn feeding period, intake could not account for this difference, as it was only slightly reduced compared to the study of Guy et al. [6] (268 vs $277 \mathrm{~g}$ DM/bird/ day; $-3 \%$ ). Fernandez et al. [9] showed a high correlation between feed intake over the first three weeks of spontaneous corn feeding and liver weight after 12 weeks of spontaneous corn feeding. Over these three weeks, feed intake was lower in our study (246 g DM/bird/day) compared to the study of Guy et al. [6] (301 g DM/bird/day; - 18\%) thus partly explaining the differences in liver weights. Unlike previous studies, birds had access to a grassland before corn feeding that could have impacted on the subsequent fattening. Vitamins $\mathrm{C}$ and $\mathrm{E}$ for example modulate lipid metabolism in mammals $[59,60]$. However, neither the nature (plant types) and composition of the grass nor intake level were measured in this study. It is therefore difficult to evaluate the nutritional impact of this procedure upon the subsequent steatosis observed.

\section{Conclusion}

Correlations between microbiota and steatosis are being extensively studied in mammals, and causal relations have been evidenced. Our study is the first to evaluate the intestinal microbial composition in association with steatosis, whether spontaneous or induced by overfeeding, in geese. We evidenced that performances, biochemical composition of the livers and microbiota differed considerably in response to steatosis stimulation mode. We namely identified the genus Romboutsia to be overrepresented in birds developing a spontaneous steatosis in comparison to those submitted to conventional overfeeding while the genera Ralstonia, Variovorax and Sphingomonas were underrepresented only in birds that did not develop a spontaneous steatosis compared to conventionally overfed ones, birds developing a spontaneous steatosis having intermediate values. Secondly, no overall differences in microbial composition were evidenced in association with different aptitudes to spontaneous steatosis. Thus, unlike what can be observed in mammals, no clear microbial signature associated with spontaneous steatosis level was identified. It would however be of interest to further investigate the correlations and potential causal associations between the digestive microbiota and steatosis in waterfowl in studies with greater disparities in steatosis level. Furthermore, migratory birds have a specific ability to develop a transitory steatosis during the pre-migratory period. However, the biomimetic features of the alternative system presented here are limited to certain features such as the light stimulation and the period of the year. Animals being reared with a specific high starch diet over a prolonged timespan it would be of interest to evaluate the associations between microbiota and metabolic and immune mechanisms occurring in the liver and adipose tissue under spontaneous steatosis as initiated in control [61] and overfed geese [15].

\section{Supplementary Information}

The online version contains supplementary material available at https://doi. org/10.1186/s42523-020-00067-z.

Additional file 1: Supplemental Figure 1. Ambiant temperature and hygrometry in the experimental facility during the Ad libitum feeding (AF) period in the alternative breeding system (161 to 245 days of age). 
Supplemental Figure 2. Selection of PosSF and NegSF birds after the Ad libitum feeding period (245 days of age) in the alternative system. A) Body composition and B) biochemical composition of the livers in the different groups

Additional file 2: Supplemental Table 1. Pairwise Adonis tests between groups. Supplemental Table 2 Relative abundance (\%) of the top 10 OTUs contributing to PLS-DA axis 1 on PosSF and NegSF groups. Supplemental Table 3. Relative taxonomic abundance (in \%) in ileal content at phyla level according to the experimental group. Supplemental Table 4. Relative taxonomic abundance (in \%) in ileal content at family level according to the experimental group. Supplemental Table $\mathbf{5}$ Relative taxonomic abundance (in \%) in ileal content at genus level according to the experimental group.

Additional file 3. Biochemical and slaughter performances data set.

\section{Abbreviations}

AF: Ad libitum feeding; Alt:: Alternative rearing system; AMEn: Apparent Metabolisable Energy, nitrogen-corrected; BW: Body Weight; $C_{\text {alt: }}$ Control group before ad libitum corn mixture feeding; $C_{\text {conv }}$ : Control group before overfeeding; CF: Controlled Feeding; CO: Conventional Overfeeding; Conv: Conventional rearing system; CP: Crude Protein; DM: Dry Matter; MM: Mineral Matter; NAFLD: Non Alcoholic Fatty Liver Diseases; NASH: NonAlcoholic Steatohepatitis; NegSF: Negative response to spontaneous steatosis stimulation group; nMDS: Non-Metric Dimensional Scaling; OF: Overfed group; OTU: Operational Taxonomic Unit; PLS-DA: Partial Least Squares Discriminant Analyzis; PosSF: Positive response to spontaneous steatosis stimulation group; SF: Spontaneous Fattening

\section{Acknowledgements}

We thank Hélène Manse for performing the biochemical analyses and the Get-PlaGe INRAE team for the MiSeq sequencing of our samples. We are grateful to the Genotoul bioinformatics platform Toulouse Occitanie (bioinfo Genotoul, doi: https://doi.org/10.15454/1.5572369328961167E12) for providing computing and storage resources. The advice and technical assistance of the staff of the goose and ducks Breeding Station (Coulaures, France), especially C. Mondoux, are acknowledged

\section{Authors' contributions}

C.K., J.A. and K.R. conceived the experiment. J.A. and F.L. conducted the in vivo experiment. M.E. conducted laboratory analyses. G.P. and C.K. performed microbial bioinformatics analyses. C.K. and L.C. performed statistical analyses. C.K., S.C. and K.R. wrote the report. J.A., M.E., L.C., G.P., X.F. and S.D. provided intellectual input and contributed to the writing of the report. All authors read and approved the final manuscript.

\section{Funding}

The study was funded by the 'Comité Interprofessionel des Palmipèdes à Foie Gras (CIFOG) and the 'Direction Générale de l'Alimentation (DGAL)'. M. Even was a beneficiary of a financial support from the 'Conseil Départemental des Landes'.

\section{Availability of data and materials}

All raw sequences were deposited in the NCBI Sequence Read Archive (SRA) under accession number PRJNA634833. Data concerning slaughter performances and biochemical composition of the livers are available as supplemental material to this article.

\section{Ethics approval and consent to participate}

The trial was carried out at the Goose and Duck Breeding Station (Coulaures, Dordogne, France), which has experimental approval A24-137-1. The procedure to measure crop development received the authorization number APAFIS\#2261-2015100215034522v3 from the French Ministry of National Education, Higher Education and Research. Technical staff and scientists all had individual authorizations to conduct animal experimentation in accordance with good animal practices issued by the DDCSPP (Direction Départementale de la Cohésion Sociale et de la Protection des Populations) and slaughter was performed according to the European Council regulations [18].

\section{Consent for publication}

Not applicable.

\section{Competing interests}

The authors declare that they have no competing interests.

\section{Author details}

${ }^{1}$ GenPhySE, Université de Toulouse, INRAE, ENVT, F-31326 Castanet Tolosan, France. ${ }^{2}$ ASSELDOR, Station d'expérimentation appliquée et de démonstration sur l'oie et le canard, La Tour de Glane, 24420 Coulaures, France. ${ }^{3}$ Université de Pau et des Pays de I'Adour, E2S UPPA, INRAE, NUMEA, Saint-Pée-sur- Nivelle, 64310 Pau, France.

Received: 17 June 2020 Accepted: 8 December 2020 Published online: 06 January 2021

\section{References}

1. Odum EP. Premigratory hyperphagia in birds. Am J Clin Nutr. 1960;8:621-9.

2. Pond CM. Morphological aspects and the ecological and mechanical consequences of fat deposition in wild vertebrates. Annu Rev Ecol Syst. 1978;9:519-70.

3. Bairlein F, Gwinner E. Nutritional mechanisms and temporal control of migratory energy accumulation in birds. Annu Rev Nutr. 1994;14:187-215.

4. King JR, Farner DS. Studies of fat deposition in migratory birds. Ann N Y Acad Sci. 1965;131(A1):422-40.

5. Heikkinen ME, Ruokonen M, Alexander M, Aspi J, Pyhajarvi T, Searle JB. Relationship between wild Greylag and European domestic geese based on mitochondrial DNA. Anim Genet. 2015;46(5):485-97.

6. Guy G, Fortun-Lamothe L, Benard G, Fernandez X. Natural induction of spontaneous liver steatosis in Greylag Landaise geese (Anser anser). J Anim Sci. 2013:91(1):455-64

7. Davail S, Guy G, Andre JM, Hermier D, Hoo-Paris R. Metabolism in two breeds of geese with moderate or large overfeeding induced liver-steatosis. Comp Biochem Physiol A Mol Integr Physiol. 2000;126(1):91-9.

8. Brachet M, Guy G, Fernandez X, Arroyo J, Fortun-Lamothe L, editors. Environmental impacts of the goose foie gras production: comparison of systems with or without force-feeding. 11 èmes Journées de la Recherche Avicole et Palmipedes a Foie Gras; 201525 et 26 mars. France: Tours; 2015.

9. Fernandez X, Guy G, Laverze JB, Bonnefont C, Knudsen C, Fortun-Lamothe L. A kinetic study of the natural induction of liver steatosis in Greylag Landaise geese: the role of hyperphagia. Animal. 2016;10(8):1288-95.

10. Safari Z, Gerard P. The links between the gut microbiome and non-alcoholic fatty liver disease (NAFLD). Cell Mol Life Sci. 2019;76(8):1541-58.

11. Kraimi N, Dawkins M, Gebhardt-Henrich SG, Velge P, Rychlik I, Volf J, et al. Influence of the microbiota-gut-brain axis on behavior and welfare in farm animals: a review. Physiol Behav. 2019;210:112658.

12. Vasai F, Ricaud KB, Bernadet MD, Cauquil L, Bouchez O, Combes S, et al. Overfeeding and genetics affect the composition of intestinal microbiota in Anas platyrhynchos (Pekin) and Cairina moschata (Muscovy) ducks. FEMS Microbiol Ecol. 2014;87(1):204-16.

13. Vasai F, Ricaud KB, Cauquil L, Daniel P, Peillod C, Gontier K, et al. Lactobacillus sakei modulates mule duck microbiota in ileum and ceca during overfeeding. Poult Sci. 2014;93(4):916-25.

14. Even M, Davail S, Rey M, Tavernier A, Houssier M, Bernadet MD, et al. Probiotics strains modulate gut microbiota and lipid metabolism in mule ducks. Open Microbiol J. 2018;12:71-93

15. Liu L, Zhao X, Wang Q, Sun XX, Xia LL, Wang QQ, et al. Prosteatotic and protective components in a unique model of fatty liver: gut microbiota and suppressed complement system. Sci Rep. 2016;6:31763.

16. Knudsen C, Bonnefont C, Fortun-Lamothe L, Ricaud K, Fernandez X. Spontaneous liver steatosis in waterfowls: overview on current research and perspectives. INRA Prod Anim. 2018;31(2):117-29.

17. Fernandez X, Lazzarotto V, Bernadet MD, Manse H. Comparison of the composition and sensory characteristics of goose fatty liver obtained by overfeeding and spontaneous fattening. Poult Sci. 2019;98(11):6149-60.

18. Council regulation (EC) No 1099/2009 of 24 September 2009 on the protection of animals at the time of killing, 1099/2009 (2009).

19. Council NR. Nutrient requirements of poultry: ninth revised edition, 1994. Washington, DC: The National Academies Press; 1994. 176 p.

20. Arroyo J, Lavigne F, Bannelier C, Fortun-Lamothe L. Influence of the incorporation mode of sugar beet pulp in the finishing diet on the 
digestive tract and performances of geese reared for foie gras production. Poult Sci. 2017:96(11):3928-37.

21. Mattocks JG. Goose feeding and cellulose digestion. 1971.

22. Bonnefont $\mathrm{C}$, Leotoing d'Anjony $\mathrm{H}$, Guy G, Laverze J-B, Brachet M, FortunLamothe $L$, et al., editors. Effect of light programs on the spontaneous fattening of goose liver without over-feeding. $11^{\text {èmes }}$ Journées de la Recherche Avicole et Palmipedes a Foie Gras; 201525 et 26 mars 2015; Tours, France.

23. Arroyo J, Auvergne A, Dubois JP, Lavigne F, Bijja M, Bannelier C, et al. Effects of presentation and type of cereals (corn or sorghum) on performance of geese. Poult Sci. 2012;91(8):2063-71.

24. A.O.A.C. AOAC Official Method 968.06. Protein (Crude) in Animal Feed. Dumas Method. In: Horwitz W, Latimer GW, editors. AOAC Official Methods of Analysis. Chap. 4. Gaitherburg: AOAC International; 2005. p. 25-6.

25. Folch J, Lees M, Sloane Stanley GH. A simple method for the isolation and purification of total lipides from animal tissues. J Biol Chem. 1957;226(1): 497-509.

26. Dalrymple RH, Hamm R. A method for the extraction of glycogen and metabolites from a single muscle sample. Int J Food Sci Technol. 1973;8(4): 439-44.

27. Lactate Dehydrogenase. In: Bergmeyer HU, editor. Methods of Enzymatic Analysis (Second Edition). 2: Academic Press; 1974. p. 574.

28. Escudie F, Auer L, Bernard M, Mariadassou M, Cauquil L, Vidal K, et al. FROGS: find, rapidly, OTUs with galaxy solution. Bioinformatics. 2018;34(8): 1287-94.

29. Bokulich NA, Subramanian S, Faith JJ, Gevers D, Gordon Jl, Knight R, et al. Quality-filtering vastly improves diversity estimates from Illumina amplicon sequencing. Nat Methods. 2013;10(1):57-9.

30. Quast C, Pruesse E, Yilmaz P, Gerken J, Schweer T, Yarza P, et al. The SILVA ribosomal RNA gene database project: improved data processing and webbased tools. Nucleic Acids Res. 2013;41(Database issue):D590-D6.

31. McMurdie PJ, Holmes S. phyloseq: an R package for reproducible interactive analysis and graphics of microbiome census data. PLoS One. 2013;8(4):e61217.

32. Rohart F, Gautier B, Singh A, Lê Cao K-A. mixOmics: An R package for 'omics feature selection and multiple data integration. PLoS Comp Biol. 2017; 13(11):e1005752.

33. Bonnefont CMD, Molette C, Lavigne F, Manse H, Bravo C, Lo B, et al. Evolution of liver fattening and foie gras technological yield during the overfeeding period in mule duck. Poult Sci. 2019;98(11):5724-33.

34. Hermier D, Salichon MR, Guy G, Peresson R, Mourot J, Lagarrigue S. Hepatic steatosis in waterfowl: metabolic basis and genetic susceptibility. INRA Prod Anim. 1999;12(4):265-71.

35. Ricaud K, Even M, Lavigne F, Davail S, Arroyo J. Evolution of intestinal microbiota and body compartments during spontaneous hyperphagia in the Greylag goose. Poult Sci. 2019;98(3):1390-402.

36. Yang H, Xiao Y, Gui G, Li J, Wang J, Li D. Microbial community and shortchain fatty acid profile in gastrointestinal tract of goose. Poult Sci. 2018; 97(4):1420-8.

37. Liu G, Luo X, Zhao X, Zhang A, Jiang N, Yang L, et al. Gut microbiota correlates with fiber and apparent nutrients digestion in goose. Poult Sci. 2018;97(11):3899-909.

38. Waite DW, Taylor MW. Characterizing the avian gut microbiota: membership, driving influences, and potential function. Front Microbiol. 2014;5:223.

39. Zeng Q, Li D, He Y, Li Y, Yang Z, Zhao X, et al. Discrepant gut microbiota markers for the classification of obesity-related metabolic abnormalities. Sci Rep. 2019;9(1):13424.

40. Li H, Liu F, Lu J, Shi J, Guan J, Yan F, et al. Probiotic mixture of Lactobacillus plantarum strains improves lipid metabolism and gut microbiota structure in high fat diet-fed mice. Front Microbiol. 2020;11:512.

41. Do MH, Lee HB, Lee E, Park HY. The Effects of Gelatinized Wheat Starch and High Salt Diet on Gut Microbiota and Metabolic Disorder. Nutrients. 2020; 12(2):301.

42. Udayappan SD, Kovatcheva-Datchary P, Bakker GJ, Havik SR, Herrema H, Cani PD, et al. Intestinal Ralstonia pickettii augments glucose intolerance in obesity. PLoS One. 2017;12(11):e0181693-e.

43. Lelouvier B, Servant F, Paisse S, Brunet AC, Benyahya S, Serino M, et al. Changes in blood microbiota profiles associated with liver fibrosis in obese patients: A pilot analysis. Hepatology (Baltimore, Md). 2016;64(6):2015-27.

44. Aron-Wisnewsky J, Vigliotti C, Witjes J, Le P, Holleboom AG, Verheij J, et al. Gut microbiota and human NAFLD: disentangling microbial signatures from metabolic disorders. Nat Rev Gastroenterol Hepatol. 2020;17(5):279-97.
45. Ranjitkar S, Lawley B, Tannock G, Engberg RM. Bacterial succession in the broiler gastrointestinal tract. Appl Environ Microbiol. 2016;82(8):2399-410.

46. Lu J, Idris U, Harmon B, Hofacre C, Maurer JJ, Lee MD. Diversity and succession of the intestinal bacterial community of the maturing broiler chicken. Appl Environ Microbiol. 2003;69(11):6816-24.

47. Rey M, Brugirard-Ricaud K, Bernadet MD, Pascal G, Combes S, Cauquil L, et al. Implantation of ileal and cecal microbiota in Anas platyrhynchos (Pékin), Cairina moschata (Muscovy) and mule ducklings using Miseq sequencing. $11^{\text {èmes }}$ Journées de la Recherche Avicole et Palmipedes a Foie Gras; 201525 et 26 mars. France: Tours; 2015.

48. Xu Q, Yuan X, Gu T, Li Y, Dai W, Shen X, et al. Comparative characterization of bacterial communities in geese fed all-grass or high-grain diets. PLoS One. 2017;12(10):e0185590.

49. Guo B, Li D, Zhou B, Jiang Y, Bai H, Zhang Y, et al. Comparative characterization of bacterial communities in geese consuming of different proportions of ryegrass. PLoS One. 2019;14(10):e0223445.

50. Tao S, Tian P, Luo Y, Tian J, Hua C, Geng Y, et al. Microbiome-Metabolome responses to a high-grain diet associated with the hind-gut health of goats. Front Microbiol. 2017:8:1764

51. Le Floc'h N, Knudsen C, Gidenne T, Montagne L, Merlot E, Zemb O. Impact of feed restriction on health, digestion and faecal microbiota of growing pigs housed in good or poor hygiene conditions. Animal. 2014;8(10):163242.

52. Siegerstetter SC, Petri RM, Magowan E, Lawlor PG, Zebeli Q, O'Connell NE, et al. Feed restriction modulates the fecal microbiota composition, nutrient retention, and feed efficiency in chickens divergent in residual feed intake. Front Microbiol. 2018:9:2698.

53. Combes S, Massip K, Martin O, Furbeyre H, Cauquil L, Pascal G, et al. Impact of feed restriction and housing hygiene conditions on specific and inflammatory immune response, the cecal bacterial community and the survival of young rabbits. Animal. 2017;11(5):854-63.

54. McCormack UM, Curiao T, Buzoianu SG, Prieto ML, Ryan T, Varley P, et al. Exploring a Possible Link between the Intestinal Microbiota and Feed Efficiency in Pigs. Appl Environ Microbiol. 2017;83(15):e00380-17.

55. Yan W, Sun C, Yuan J, Yang N. Gut metagenomic analysis reveals prominent roles of Lactobacillus and cecal microbiota in chicken feed efficiency. Sci Rep. 2017;7:45308.

56. Verschuren LMG, Calus MPL, Jansman AJM, Bergsma R, Knol EF, Gilbert H, et al. Fecal microbial composition associated with variation in feed efficiency in pigs depends on diet and sex. J Anim Sci. 2018;96(4):1405-18.

57. Le Roy T, Llopis M, Lepage P, Bruneau A, Rabot S, Bevilacqua C, et al. Intestinal microbiota determines development of non-alcoholic fatty liver disease in mice. Gut. 2013;62(12):1787-94.

58. Hamid H, Zhang JY, Li WX, Liu C, Li ML, Zhao LH, et al. Interactions between the cecal microbiota and non-alcoholic steatohepatitis using laying hens as the model. Poult Sci. 2019;98(6):2509-21.

59. D'Adamo E, Marcovecchio ML, Giannini C, de Giorgis T, Chiavaroli V, Chiarell $\mathrm{F}$, et al. Improved oxidative stress and cardio-metabolic status in obese prepubertal children with liver steatosis treated with lifestyle combined with vitamin E. Free Radic Res. 2013;47(3):146-53.

60. Oliveira C, Gayotto L, Tatai C, Della Nina BI, Janiszewski M, Abdalla D, et al. Protective effect of vitamin $C$ in experimental liver steatosis. Gastroenterology. 2002;122(4):A675-A.

61. Gao G, Zhao X, Li Q, He C, Zhao W, Liu S, et al. Genome and metagenome analyses reveal adaptive evolution of the host and interaction with the gut microbiota in the goose. Sci Rep. 2016;6:32961.

\section{Publisher's Note}

Springer Nature remains neutral with regard to jurisdictional claims in published maps and institutional affiliations. 